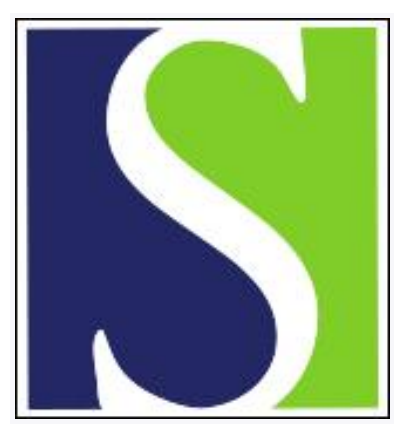

Scand J Work Environ Health 1981;7(3):204-213

https://doi.org/10.5271/sjweh.3113

Issue date: Sep 1981

Testicular function of men occupationally exposed to para-tertiary butyl benzoic acid

by Whorton MD, Stubbs HA, Obrinsky A

Affiliation: Environmental Health Associates, Inc; Berkeley; CA 94704, United States.

Key terms: exposure; gonadotropin level; infertility; man; men; occupational exposure; para-tertiary butyl benzoic acid; sperm-count; sperm-count suppression; testicular effect; testicular function

This article in PubMed: www.ncbi.nlm.nih.gov/pubmed/20120586 


\title{
Testicular function of men occupationally exposed to para-tertiary butyl benzoic acid
}

\author{
by M Donald Whorton, MD, MPH, Harrison A Stubbs, PhD, Allen Obrinsky, BS, \\ Thomas $\mathrm{H}$ Milby, MD, MPH ${ }^{1}$
}

\begin{abstract}
WHORTON MD, STUBBS HA, OBRINSKY A, MILBY TH. Testicular function of men occupationally exposed to para-tertiary butyl benzoic acid. Scand $j$ work environ health 7 (1981) 204-213. The possible testicular effects resulting from occupational exposure to para-tertiary butyl benzoic acid (p-TBBA) were studied in 90 male volunteers employed at the Martinez, California, facility of the Shell Chemical Company. The comparison data used were obtained from an external reference group of 103 male volunteers not exposed to any known testicular toxin. Exposure indices were based on the calendar years of employment in a given job category. Outcome variables included sperm count, history of fathering children, and gonadotropin levels. It was concluded that p-TBBA, at the levels of exposure experienced at this plant, does not have an apparent clinical or epidemiologic effect on testicular function.
\end{abstract}

Key terms: gonadotropin levels, infertility, sperm-count suppression, testicular effects.

With the findings in 1977 of severe testicular effects in humans associated with exposure to dibromochloropropane (DBCP) $(1,6)$, other chemicals with demonstrated evidence of adverse testicular effects in animals are now being evaluated to determine if any such effects are present in exposed workers.

Para-tertiary butyl benzoic acid ( $p$ TBBA) is an organic acid used in cutting oil and in paint formulations. Eight of 18 rats fed large amounts of p-TBBA [500$1,000 \mathrm{mg} / \mathrm{kg}(2.8-5.6 \mathrm{mmol} / \mathrm{kg})]$ showed evidence of testicular atrophy with degeneration of the spermatogenic elements of the seminiferous tubules (3). A subacute oral toxicity study was done by placing ten animals of each sex into six groups, each group being fed diets containing 0,100 , $316,1,000,3,160$ or $10,000 \mathrm{ppm}$ of $\mathrm{p}$-TBBA, respectively, for $90 \mathrm{~d}$. At the highest dose levels, the number of erythrocytes were decreased. At the highest two exposures,

1 Environmental Health Associates, Inc, Berkeley, California, United States

Reprint requests to: Dr MD Whorton, Environmental Health Associates, Inc, 2150 Shattuck Avenue, Suite 414, Berkeley, CA 94704, USA. there was toxic degeneration of the parenchymal cells and sinusoidal congestion of the liver. The genitourinary system was the most dramatically affected, with gross changes including hydronephrosis, hydroureter, ureteral obstruction, hematuria, and bilateral testicular atrophy. The renal damage was consistent with acute tubular necrosis, while the toxic effect of the testicular toxicity was located in the seminiferous tubules. The severity of injury was related to amount of exposure, but the lesions were found in the lowest exposure group (100 ppm) (3).

Since the effects of p-TBBA in man have not been systematically evaluated, especially the testicular effects, workers exposed to this chemical were studied.

\section{Background of production activities}

In $1954 \mathrm{p}$-TBBA production began at the Martinez, California, facility of the Shell Chemical Company. During the period 1955-1963, a Schmig scrubber-type system was used to assist in reducing the amount of dust produced by the operation 
of the p-TBBA unit. Prior to 1975 the unit was located on the first floor of a totally enclosed building with the control room located on the second floor. In 1957 certain of the walls were removed and, during 1958-1959, the remaining walls were removed to facilitate the reduction of airborne dust levels by natural ventilation. Comments from personnel in adjacent operations indicated that dust emissions continued in noticeable amounts. The pTBBA unit did not normally operate during the summer months.

Operators responsible for p-TBBA production make periodic trips from the external control room to obtain samples and check the operations of the unit. They spend, on the average, $1 \mathrm{~h} / \mathrm{d}$ in the unit with the remainder of their work time spent in the control room. Product drummers spend $80 \mathrm{~min} /$ shift filling large drums with p-TBBA. They spend 80-90 $\mathrm{min}$ in set-up/clean-up and another 60 min taking gauge readings. The remainder of the shift is spent drumming another product.

Maintenance operations are performed primarily by pipefitters, machinists, and instrument men who actually service the p-TBBA unit on a work order basis. Daily work assignment records do not exist for maintenance personnel.

Routine maintenance operations consist of changing a process filter approximately once a month, unplugging stoppages in pipes and equipment, and repairing pumps. Pump maintenance is performed in the maintenance shop by machinists after the pumps are disconnected by pipefitters and removed to the shop.

Shipping personnel transport full drums of $\mathrm{p}$-TBBA to the warehouse and are responsible for loading drums onto trucks for delivery.

Each day, the quality control laboratory analyzes 30 samples of p-TBBA from the three workshifts. Each sample weighs approximately five pounds $(2.3 \mathrm{~kg})$. Only about $25 \mathrm{~g}$ is used for each analysis. Samples are analyzed for melt color, melting point, ash percentage, weight, and iron content (ppm). Although a specified laboratory technician usually performs most of the p-TBBA analyses, all personnel in the laboratory have frequently performed them.

\section{Methods}

\section{Introduction of program}

A list of all of the Shell employees at the facility was developed, and from it all potentially exposed male employees were invited to join the study group. This invited list included all employees who might have come in contact with p-TBBA. The excluded employees were office workers.

Each man in the invited study group was scheduled to attend a seminar discussion about the purpose of the study, requirements for participation, receipt of personal results, and confidentiality. These seminars were conducted by one of us (DW) after background remarks by the operations superintendent and the safety department manager.

\section{Classification of exposure}

An exposure categorization procedure was developed prior to any biological testing. For operators and product drummers, data contained in a log book of job assignments dating from 1969 through 1979 were abstracted for hours of p-TBBA-assigned work. Maintenance, shipping, and laboratory workers were interviewed to learn the nature of the work and possible pTBBA exposures. Salaried employees were sent a questionnaire concerning p-TBBA job assignments. The available industrial hygiene data were reviewed in order to help assess exposure. Finally, prior to the medical history, each individual had his work history examined and reassessed.

\section{Weighted relative exposure index}

Exposures were divided into three time periods: (i) prior to 1964 (prior to installation of the present scrubber system); (ii) 1964 to 1978 (prior to the initiation of personal protective practices, such as use of respirator, clothing change, shower, etc); (iii) 1978 to 1979 .

The occupations evaluated for relative exposure during each of the three exposure periods were shipping personnel, 
p-TBBA operator, p-TBBA drummer, machinist, pipefitter, instrument repairman, welder, operations foreman, maintenance foreman, laboratory (analytical) personnel, and operations management personnel.

A weighted relative exposure index for each job classification was developed based on the consensus of a panel of supervisory staff at the plant. This approach was considered appropriate, especially for past exposures, because industrial hygiene data were available only for recent years.

Yearly weighted relative exposure points ranged from a base value of one point for present-day operations staff having extremely limited contact with p-TBBA to a high of 226 points for individuals who worked as p-TBBA operators during the period prior to 1964. Thus it was estimated that, prior to 1964 , a p-TBBA operator's annual exposure was 226 times the exposure of a present-day operating management employee. Table 1 presents the weighted relative exposure point system.

An exposure index for each person was calculated based on the relative exposure point values and the amount of time in a given job. Because operators and drummers did not always work continuously in the p-TBBA unit, it was necessary to develop time-weighted factors in order to convert exposure data to annual exposure estimates. Exposure assessments for individuals other than operators and drummers were based on annual estimates without consideration for actual time of exposure to p-TBBA.

Table 1. Weighted relative exposure points - Yearly exposure points by period.a (Source: Shell p-TBBA data, 1980) ( $p-T B B A=$ para-tertiary butyl benzoic acid)

\begin{tabular}{lccr}
\hline & & \multicolumn{1}{c}{ Period } \\
\cline { 2 - 4 } Job classification & Prior to 1964 & $1964-1977$ & $1978-1979$ \\
\hline Shipping clerk & 45 & 13 & 5 \\
p-TBBA operator & 226 & 32 & 11 \\
p-TBBA drummer & 185 & 50 & 14 \\
Machinist/pipefitter & 96 & 23 & 5 \\
Instrument person & 70 & 12 & 3 \\
Welder & 2 & 2 & 1 \\
Operations foreman & 119 & 21 & 3 \\
Maintenance foreman & 104 & 19 & 3 \\
Laboratory personnel & 3 & 3 & 3 \\
Operations management personnel & 51 & 5 & 1 \\
\hline
\end{tabular}

a For example, the weighted relative exposure index for a shipping clerk employed from 1 January 1977 through 31 December 1979 would be 23 exposure points: 13 for the year 1977 and 5 each for the years 1978 and 1979.

Table 2. Weighted relative exposure classification - Frequency of the entire study group by degree of exposure and time period. (Source: Shell p-TBBA data, 1980)

\begin{tabular}{|c|c|c|c|c|c|c|}
\hline \multirow{3}{*}{ Degree of exposure } & \multicolumn{6}{|c|}{ Time period } \\
\hline & \multicolumn{2}{|c|}{$1978-1979$} & \multicolumn{2}{|c|}{$1969-1979$} & \multicolumn{2}{|c|}{$1954-1979 a$} \\
\hline & $\begin{array}{l}\text { Exposure } \\
\text { points }\end{array}$ & Frequency & $\begin{array}{l}\text { Exposure } \\
\text { points }\end{array}$ & Frequency & $\begin{array}{l}\text { Exposure } \\
\text { points }\end{array}$ & Frequency \\
\hline $\begin{array}{l}\text { High } \\
\text { Medium } \\
\text { Low } \\
\text { Minimal }\end{array}$ & $\begin{array}{c}\geq 20 \\
10-19 \\
5-9 \\
\leq 4\end{array}$ & $\begin{array}{r}3 \\
23 \\
24 \\
17\end{array}$ & $\begin{array}{c}\geq 200 \\
100-199 \\
50-99 \\
\leq 49\end{array}$ & $\begin{array}{l}10 \\
14 \\
14 \\
68\end{array}$ & $\begin{array}{c}\geq 1,000 \\
500-999 \\
100-499 \\
\leq 99\end{array}$ & $\begin{array}{l}9 \\
6 \\
9 \\
9\end{array}$ \\
\hline $\begin{array}{l}\text { Maximum possible } \\
\text { individual exposure }\end{array}$ & 28 & & 442 & & 2,510 & \\
\hline Total employees & & 67 & & 106 & & 33 \\
\hline
\end{tabular}

a Based on interviews and questionnaires only. Does not include any individuals who are presently operators or drummers. 
The following criteria were developed for the relative weighting factors for the time worked per year: more than four months, $100 \%$ of exposure index; more than two but less than four months, $50 \%$ of exposure index; more than one but less than two months, $25 \%$ of exposure index; more than one week but less than one month, $10 \%$ of exposure index; and less than one week, no contribution for that year.

Table 2 provides the distributions of all individuals by exposure classifications for the three time periods, 1978 to 1979 (past 2 a), 1969 to 1979 (past 11 a), and significant exposure prior to 1969 . In the table, exposure for each period is classified as high, medium, low, or minimal according to the value of the exposure within the time period. In addition, the maximum possible number of exposure points which an employee might obtain for each exposure period is listed at the bottom of the table.

\section{Medical evaluations}

Each participant signed an informed consent form prior to participation. The medical evaluations were based on the following: (i) self-administered questionnaire for marital and reproductive history and smoking history; (ii) administered questionnaires for work history and genitourinary medical history; (iii) a brief physical examination of the male genitalia; (iv) venous blood samples for a hemogram, chemistry panel 24 , and serum hormones [follicle stimulating hormone (FSH), luteinizing hormone (LH), and testosterone]; (v) two semen samples from nonvasectomized men.

All laboratory work was done at the Alta Bates Hospital in Berkeley, California. The blood samples were obtained at the time of each man's scheduled examination. The sera from the blood chemistries were separated shortly after clotting. The blood samples for hormone analysis were frozen and later run on a batch basis with radioimmunoassay techniques.

Semen samples, collected at home, were placed in brown paper bags and deposited in a special receptacle at a physician's office near the plant. The samples were taken on a daily basis by special courier to the laboratory for analysis, which in- cluded volume, sperm count, and a slide for sperm morphology stained with pap stain. Because we were unable to obtain and transfer specimens to the laboratory warm and within $1 \mathrm{~h}$, sperm motility was not examined.

Examinations were conducted in a vacant Shell office building located outside the main plant gate. No Shell personnel, other than the examinees, were present at the examination site during the evaluation.

Each participant was notified in writing about his results. Group results were presented at two seminar discussions by one of us (DW).

\section{Results}

\section{Industrial hygiene}

Relatively few industrial hygiene measurements have been made for p-TBBA in the unit, but those made in 1978 and 1979 indicate that exposures to p-TBBA among operators and drummers have normally ranged from less than $0.1 \mathrm{mg} / \mathrm{m}^{3}$ to 0.5 $\mathrm{mg} / \mathrm{m}^{3}$. Operators and drummers (personal sampling), as well as several areas within the unit, have been monitored for both total and respirable dust concentrations. The lowest detectible amount of p-TBBA for the analytical method used is $0.1 \mathrm{mg}$.

Although the respirable dust concentrations were substantially lower than the total dust concentrations, there has not been a sufficient number of respirable samples taken to characterize fully the exposure to this important fraction of airborne dust. Of the samples taken, the respirable fraction ranged from $21-51 \%$ of the total. It should also be noted that during an 8-h shift the product drummers spend more time drumming another product (for approximately $180 \mathrm{~min} / \mathrm{shift}$ ) than drumming p-TBBA (60 min/shift) and that unit operators normally spend most of their time away from the unit processing equipment, ie, they stay in the control room.

\section{Classification of exposure}

Based upon an examination of the p-TBBA unit operation, together with available air 
monitoring data, it appears that operators and drummers experience the greatest exposure to p-TBBA. Exposures of maintenance personnel have likely approached the peak concentrations (ie, to a maximum of $9.3 \mathrm{mg} / \mathrm{m}^{3}$ ) experienced by operators and drummers. However, on a timeweighted basis, exposure among maintenance and shipping personnel can be expected to be considerably lower than corresponding exposure values for operators and drummers because their exposure to p-TBBA is sporadic.

Laboratory technicians were considered exposed to p-TBBA by virtue of their daily contact with this product while performing quality assurance tests. The 30 p-TBBA samples processed daily include at least one sample of liquid filtrate. Two years ago personal protective procedures were implemented to avoid skin contact; prior to that time skin contact with pTBBA was common. However, laboratory personnel should be considered as receiving much less exposure than the other groups mentioned. The group of employees least exposed to p-TBBA includes supervisory personnel (shift supervisors, operations management personnel).

Based on currently available data, it would be unrealistic to attempt to formulate quantitative exposure estimates for any jobs other than operators and drummers, because no personal sampling was done for the other exposed occupations, nor has sufficient sampling been done to permit extrapolation of exposure from operators and drummers to other job classes.

\section{Biological findings}

One hundred and fifteen men comprised the potentially available study group. They were divided into five job categories: operators/drummers, maintenance, shipping, laboratory and supervisors/foremen.

Ninety $(78 \%)$ of the 115 men agreed to participate in the study. The following were the percentage participation rates by job title: operator/drummers $74 \%$ (39 of 53 ), maintenance $88 \%$ (22 of 25), shipping personnel $67 \%$ (2 of 3 ), supervision/foreman $82 \%$ (23 of 28 ) and laboratory $67 \%$ (4 of 6).
Of the 90 participants 33 had undergone a vasectomy. ${ }^{2}$ Fifty-one $(89 \%)$ of the 57 nonvasectomized participants provided at least one semen sample. Six men who promised to provide samples did not. Thirty-nine men provided two semen samples each, while 12 provided only one sample each.

Eight of the 25 nonparticipants were on vacation or extended leave during the month of December 1979, when the medical evaluations took place. Of the remaining 17 nonparticipants, 7 came to the scheduled interview while 10 declined to be interviewed.

The exposure indices for the participants providing semen samples were similar to those of the nonparticipants and nonvasectomized participants who did not provide semen samples. Table 3 provides the frequency and percentage distributions by time period and exposure index categories for these two groups and indicates that the distributions of exposure indices for the participants and nonparticipants were similar.

Analysis of the sperm count data for the 51 participants yielded a median sperm count of 72 million $/ \mathrm{ml}$ of semen. One participant $(2 \%$ ) was azoospermic (zero sperm count), and seven $(13.7 \%$ ) were oligospermic $(>0$, but $<20 \mathrm{million} / \mathrm{ml}$ ). Thus $15.7 \%$ of the test group had sperm counts in the potentially subfertile range (less than 20 million sperm cells $/ \mathrm{ml}$ ).

It was not feasible to obtain a nonexposed reference group of men from this plant. Therefore a group of 103 chemical plant workers included in previous studies were utilized as referents. These 103 men had been selected previously because they were judged not to have been exposed to agents known to be toxic to the testes (5).

The observed cumulative sperm count distribution for the p-TBBA-exposed and reference groups were compared with the use of the Kolmogorov-Smirnov two-sample test (2). No significant difference was found between the estimated distribution functions of the two groups at $\alpha=0.05$. However, this test is not sensitive to differences that may exist in the tails of the two distributions. Because the percentage

2 One individual who was physically unable to provide a sample has been included in the group of vasectomized men. 